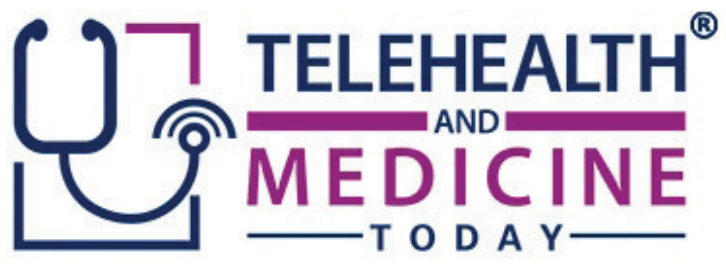

\title{
Motivational Intervention of Obesity in Primary Care Through Physical Activity Program
}

Fatima Madrona Marcos ${ }^{1}$, Josefa M. Panisello², Julio A. Carbayo Herencia ${ }^{3}$, Nuria Rosich ${ }^{4}$, Loreto Tarraga Marcos ${ }^{5}$, Josep Alins ${ }^{6}$, Pedro J. Tarraga Marcos ${ }^{7}$

Affiliations: ${ }^{1}$ EAP Zone 5A, Albacete, Spain; ${ }^{2}$ FUFOSA, Madrid, Spain; ${ }^{3}$ University Miguel Hernandez, Alicante, Spain; ${ }^{4}$ Fufosa, Barcelona, Spain; ${ }^{5}$ Clinic Hospital, Zaragoza, Spain; ${ }^{6} \mathrm{ABS}$, Barcelona, Spain; ${ }^{7}$ University Castilla la Mancha, Spain

Corresponding Author: Pedro J. Tárraga López, pjtarraga@sescam.jccm.es

Keywords: Obesity, Physical Activity, Telemedicine, Motivational Intervention

Section: Original Clinical Research

Summary: Obesity and overweight are significant public health problems, worldwide. Hence, there is the importance of developing and applying strategies that reduce weight in this population. We set out to evaluate the effectiveness of obesity intervention with three different approaches-one of them with a platform that promotes physical activity.

Methods: Randomized, controlled, parallel clinical trial that compared three arms, multicenter study in overweight or obese patients, with a 12-month follow-up. The patients were randomized into three groups: Intervention in the primary care center with intervention G1: Control group, which received the usual recommendations of losing weight following the SEEDO 2000 (Sociedad Española para el Estudio de la Obesidad)
Consensus, G2: Motivational intervention of obesity (IMOAP) with a trained nurse and small periodic work groups, and G3: IMOAP adding the use of a digital platform to record physical activity, monitors it, and, in turn, favors the practice of this (aka iwopi: the concept that physical activity has a positive impact beyond the activity). Variables collected included: weight, height, body mass index (BMI), waist circumference, lipid parameters, blood pressure, and glycosylated hemoglobin. After the interventions, clinical relevance indicators were studied. Relative risk (RR), absolute risk reduction (ARR), relative risk reduction ( $R R R)$, and number needed to treat (NNT), both for intention to treat and for biological efficacy.

Results: Cholesterol levels in three groups were reduced. The BMI showed a general 
average reduction. Total cholesterol levels were reduced in all groups, with the largest decrease in G3. Triglyceride levels were significantly reduced in two groups. Glycosylated hemoglobin showed a slight decrease that did not reach a statistically significant value.

Conclusions: The digital health platform that stimulates physical activity added to an interventionist motivation in patients with overweight or obesity is a significant additional benefit in terms of weight loss results, BMI reduction, and lipid profile in patients affected by overweight or obesity, and a most effective cost.

$\mathrm{T}$ The prevalence of obesity has reached epidemic levels in recent decades, with obesity becoming a global pandemic., ${ }^{1,2}$ Consequently, we are witnessing an increase in some diseases associated with obesity, such as type 2 diabetes, metabolic syndrome, heart disease, and certain cancers. Today, obesity prevalence is a serious public health issue in Spain. In fact, according to a recent data, $60.9 \%$ of the adult population between 25 and 64 years old are overweight or obese. ${ }^{3}$

Many environmental, behavioral, physiological, and genetic factors contribute to overweight and obesity, with a positive energy balance as the common underlying characteristic leading to these conditions. Predisposing factors combined with attenuated metabolic responses to environmental exposures and low overall energy expenditure can contribute to this positive energy balance.

Comprehensive lifestyle management is the fundamental approach for controlling weight loss and obesity and is appropriate for all people who are candidates for the treatment. ${ }^{4,5}$ Three main components of the comprehensive lifestyle management are reduced calorie intake, increased physical activity, and behavioral intervention. The Expert Panel of the NIH Obesity Education Initiative suggested a caloric deficit of 500-1,000 kcal/day using an individualized dietary strategy. ${ }^{6}$

Although exercise is more effective in preventing obesity, it can also contribute to weight loss and long-term weight maintenance. However, adherence to the prescribed levels of exercise is generally low, and in that context, integration of more physical activity as part of a general change in lifestyle (e.g., more walking and climbing stairs as part of the daily routine) can be as successful in promoting weight loss, as it is a structured exercise program. ${ }^{7,8}$

In addition, behavioral intervention is essential because it imparts strategies to patients, such as modification of signals leading to unwanted behaviors and self-control, which promote treatment compliance and achievement of diet and physical activity goals. ${ }^{9}$ In this way, obtaining better adherence to these components is associated with greater weight loss. ${ }^{10}$

The results of the Diabetes Prevention Program and Look AHEAD (Action for Health in Diabetes) testing and the National Weight Control Registry demonstrate that self-control is a critical component of behavior modification for weight loss. Consequently, the American College of Cardiology, the American Heart Association, and The Obesity Society treatment guidelines include regular self-control of food intake, physical activity, and weight as part of a structured behavior change program that support compliance with the diet and health goals.

Therefore, all interventions proved useful should be intensive, well-structured, and address multiple aspects. This implies a significant and growing investment in time and human resources 
in our health system. ${ }^{11-13}$ Accordingly, we need strategies that allow the use effective approaches that consume less resources and/or obtain better results allowing for intervention in a larger population.

Taking into account that it is common to work with information and communications technology (ICT), especially the Internet, this is emerging as a new strategy with different potentials capable of addressing the limitations of traditional programs. Technology-based health services enhanced or provided by the Internet (i.e., electronic health technologies) ${ }^{14}$ and, in particular, mobile technologies offer a great potential to increase the reach of public health initiatives and to improve public health..$^{15,16}$

The potential benefits can be improved by promoting the use of mobile technologies and the Internet. In 2014, there were 6,500 million mobile users worldwide, ${ }^{4}$ with mobile phone penetration rates reaching more than $70 \%$ of the population - many of whom live in European and North American countries, such as Spain $(83 \%),{ }^{5}$ Canada (78\%), the United Kingdom (75\%), the United States (73\%), and Italy (71\%).,5

Availability of ICT to a large number of the general population allows access to interventions from their home or other places that suits personal needs, thereby reducing the associated costs of traditional protocols. ${ }^{14}$ In addition, the Internet can be used at all stages of treatment and for follow-up after the intervention.

Another advantage of the Internet and computer programs is the ability to adapt to the personal characteristics and specific needs of the targetedstudy groups. As mentioned, the use of ICTbased interventions not only allows more people to be reached, but also allows access to them at any time during the intervention. This allows us to adjust the requirements to the needs and demands of an each individual, thus facilitating the achievement of an optimal result during the intervention. It also allows us to extend the follow-up period in a way that helps maintain the success of achieving a healthy lifestyle for a longer period. ${ }^{4,5}$

There is an increasing number of systematic reviews and meta-analyzes of e-health interventions for weight control. However, the most focus is only on mobile technologies. ${ }^{17,18}$

They do not offer a complete picture of the research that involves both Web 2.0 and mobile telephone technologies for weight control, in particular. In fact, although there are numerous portable technologies aimed at controlling physical activity and diet, it is unclear whether these technologies are effective in improving weight loss.

In this way, studies in our practice environment are needed to confirm the effectiveness and feasibility of such interventions in overweight and obese patients and determine whether it is worth implementing in the primary care system as a tool to address this problem. Therefore, the main objective of this study was a comparison between a standard behavioral weight loss intervention (standard intervention) and a technology-enhanced weight loss intervention (improved intervention) to confirm the strategy that leads to greater weight loss and assess whether the results ( $>5 \%$ loss of initial weight) can be maintained even after 1-year follow-up.

\section{METHODS}

\section{Study population}

The study population came from the health areas of Anoia and Barcelona in Spain. They were overweight or obese and diagnosed by their doctors during periodic health examinations and sent to the concerned health areas. 
This was a randomized, controlled, parallel design clinical trial, with three arms, 12month follow-up, and a 1:1:1 assignment ratio. Participants had to be between 25 and 70 years old, overweight or obese, and not meet any exclusion criteria. Data collection took place between July of 2017 and July of 2018.

Exclusion criteria were: (1) severe diseases (e.g., bedridden, neoplasms, and cognitive disorders); (2) secondary obesity (e.g., hypothyroidism and Cushing disease); (3) severe sensory diseases that interfere with motivational intervention (e.g., uncorrected visual and hearing impairments); (4) severe psychiatric diseases; (5) type 1 or type 2 diabetes mellitus with pharmacological treatment; (6) hypertension with pharmacological treatment; or (7) a diagnosis of dyslipidemia with pharmacological treatment.

Study participants signed an informed consent approved by the Ethics Committee of the area. Then, patients were randomized into three groups (Figure 1).

- G1: Control group, received usual recommendations for weight lose following the SEEDO 2000 "Consensus."

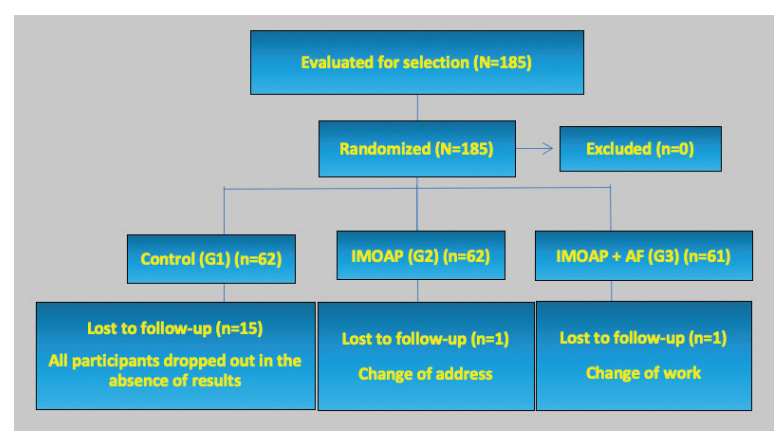

Figure 1-Study flow chart. The control group followed the general advice established to lose weight in their health centers. IMOAP: motivational intervention of obesity. AF physical activity. Source: 2018 iwopi participant guide
- G2: Motivational intervention of obesity (IMOAP) every 15 days, during weeks $1-12$ and then monthly from week 13 to the end of study. Each session lasted 1 hour, as was described in the original report. ${ }^{19}$

- G3: IMOAP adding a digital platform (Figure 2) to record physical activity, monitor it, and, in turn, supports the iwopi practice, as described here (www.iwopi.org).

A digital platform that monitors and favors physical activity was added to the G1 intervention. This platform allows registration of physical activity and donation of any of the social causes that exist in the platform. For example, the kilometers covered are donated to a Spanish association against cancer. As stated on the its website, iwopi is a sport and solidarity social network connecting people, businesses, and societies that participate in social projects, donating the miles and kilometers they run every day. Its methodology is based on the science of behavior and behavioral activation whose objective is to generate the necessary motivation to boost physical activity and subsequently achieve healthy lifestyle habits.

The ability to motivate and activate users is realized through elements of social gamification based on the improvement of physical, mental, and social well-being. Among these elements of social gamification, iwopi promotes programs and emotional, collective, and collaborative challenges to stimulate physical activity and social relations with a solidary purpose. Users can monitor their physical activity through specific physical activity apps, devices (e.g., wearables, smartwatches, and GPS watches), or through a smartphone and systems such as Apple Health or Google Fit, turning their movement into a real social impact.

The technical characteristics are: development languages: HTML5, CSS3 (Cascading 

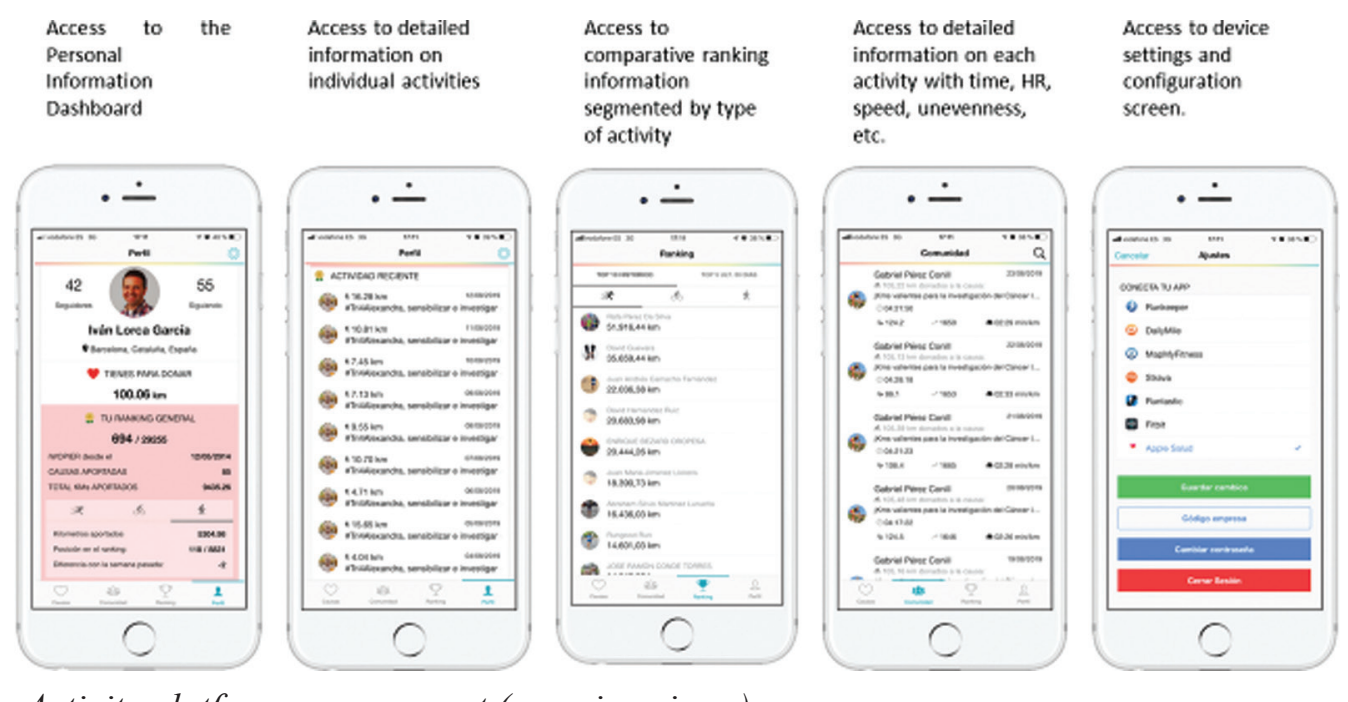

Figure 2-Activity platform management (www.iwopi.org).

Source: 2018 iwopi participant guide

Style Sheets), JavaScript; Programming languages (backend): Scala; databases: MySQL (a programming language); servers: Apache Technology; application desktop: Play framework-Boostrap; mobile development technology apps: Ionic; and Security certificate: Comodo SSL Premium Wildcard. Its single-page application structure allows for fluid interaction; and the responsive design allows adaptation to any modern browser (e.g., desktop, tablet, or mobile) without changing the design or functionalities. This helps the user interact on any of their devices and simplifies the learning curve, because the interaction is similar. The application can be found in Google Play and Apple Store. The app advises to increase the physical activity liked most (e.g., cycling, swimming, dancing, and running) every day. The connection is automatized once installed.

After signing consent, participants were randomly assigned one of the three groups using a table of random numbers. The examining team and the researcher performing the data analysis were blinded.
Statistical analysis was conducted with the SPSS, version 23. The quantitative variables are presented as mean and standard deviation (SD), and the qualitative variables are presented as absolute and relative frequencies. The ANOVA test (analysis of variance of repeated measures) was used to verify that the three groups showed no significant differences in the primary variables considered at the beginning of the study. If there were significant differences between any of the groups, Bonferroni's posterior contrast was applied.

In the comparison of means during follow-up, ANOVA was used. When the criteria for normality and sphericity were not met, Friedman's non-parametric test was applied. For independent and paired groups, differences between the means were calculated using Student's $t$-test.

After interventions, comparisons between groups were made with indicators of clinical relevance, that is, relative risk (RR), absolute risk reduction (RAR), relative risk reduction (RRR), and the number of patients to be treated (NNT). 
The analysis was performed by intention-to-treat. An attempt was made to follow the CONSORT checklist, which reports the performance of randomized clinical trials of parallel groups. ${ }^{20}$ Values whose comparisons reached a value of $p \leq 0.05$ were considered statistically significant.

The study was carried out following the recognized Deontological Standards and the Standards of Good Clinical Practice. Data were protected from uses not allowed by people outside the investigation, and confidentiality was respected on the Protection of Personal Data and the law 41/2002 of November 14, regulating autonomy of the patient and rights and obligations regarding information and clinical documentation. Therefore, the information generated in this study is strictly confidential among the participating parties.

\section{RESULTS}

There were 185 obese or overweight patients who participated (62 in G1 control usual care control, 62 G2 IMOAP intervention, and 61 G3 intervention with IMOAP + Physical Activity Program), of which 168 (47 in G1, 61 in G2, and 60 in G3) completed the study. During follow-up, 15 participants were lost to follow-up among G1 patients who did not perceive benefits with the follow-up and preferred to leave. There was also one in the G2 group for change of address, and one in the G3 group due to a change in the employment.

The overall average age was $45.6(\mathrm{SD}=12.8)$; $57.2 \%$ were women, and $42.8 \%$ were men.

Table 1 shows the main characteristics measured in each of the groups, showing only a significant difference in glycosylated hemoglobin, without the difference being clinically relevant, thus indicating the effectiveness of the randomization of the groups.
Tables 2 to 5 show how the anthropometric parameters (weight, body mass index [BMI], and waist circumference), blood pressure (systolic blood pressure [PAS] and diastolic blood pressure [PAD]), and analytical (total cholesterol, High density lipoprotein cholesterol (cHDL), triglycerides, glycemia, and $\mathrm{HbA} 1 \mathrm{c}$ ) parameters decrease (cHDL increases) at the conclusion of the study in the intervention groups significantly, with the most marked differences in the group that used the AF platform. However, the number of steps increases more in this group, which could help explain the greater differences of the rest of the parameters observed in it.

The changes in BMI can be distinguished as early as 15 days after the beginning of the different modalities of weight loss made in each of the groups. Figure 3 shows that BMI is in continuous decline to 6 months. The greatest decrease is in the IMOAP-AP group. This is followed by a slight increase in each group at 1 year of follow-up.

Figure 4 shows the percentage of weight loss, BMI, and PC achieved at the end of the year of follow-up in each group. There is a greater reduction in the intervention groups than in the control group, and among the groups of intervention who applied the AF platform.

Figure 5 shows the percentage of patients who achieved the objective of reducing their weight by at least $5 \%$ after 1 year. In line with what was observed in Figure 4, the percentage of participants assigned to the intervention groups was higher than that achieved by the control group and higher in the group that applied the PA platform.

Table 6 shows the clinical relevance analyzed. All comparisons are significant, with very low NNTs (number needed to treat), meaning that very few patients with IMOAP or IMOAP-AP need to 
Table 1. Baseline data of the sample by groups

\begin{tabular}{|c|c|c|c|c|}
\hline & $\begin{array}{l}\text { Control } \\
(n=47)\end{array}$ & $\begin{array}{l}\text { IMOAP } \\
(n=61)\end{array}$ & $\begin{array}{c}\text { IMOAP +AF } \\
\quad(n=60)\end{array}$ & $P$ \\
\hline Women/men $(n ; \%)$ & $\begin{array}{l}35(56.5) / \\
27(43.5)\end{array}$ & $\begin{array}{l}35(57.4) / \\
26(42.6)\end{array}$ & $\begin{array}{l}34(56.7) / \\
26(43.3)\end{array}$ & 0.994 \\
\hline Age (mean years \pm SD) & $45.8(12.4)$ & $44.4(12.0)$ & $47.1(12.4)$ & 0.446 \\
\hline Basal weight (mean $\mathrm{kg} \pm \mathrm{SD})$ & $83.2(13.0)$ & $88.8(14.3)$ & $86.8(13.2)$ & 0.068 \\
\hline $\mathrm{BMI}\left(\mathrm{kg} / \mathrm{m}^{2} \pm \mathrm{SD}\right)$ & $30.6(3.2)$ & $31.0(3.5)$ & $30.8(3.4)$ & 0.775 \\
\hline Waist circumference (mean cm SD) & $89.3(8.0)$ & $87.2(10.1)$ & $90.0(9.3)$ & 0.242 \\
\hline Basal blood glucose (mean $\mathrm{mg} / \mathrm{dL} \pm \mathrm{SD}$ ) & $92.8(6.0)$ & $93.7(5.9)$ & $94.7(5.7)$ & 0.207 \\
\hline HbA1c $($ mean $\% \pm$ SD) & $5.4(0.2)$ & $5.5(0.2)$ & $5.5(0.2)$ & $0.049 *$ \\
\hline Total cholesterol (mean mg/dL \pm SD) & $246.5(29.5)$ & $242.1(38.0)$ & $246.8(28.6)$ & 0.663 \\
\hline HDL cholesterol (mean mg/dL \pm SD) & $45.3(9.3)$ & $48.1(11.6)$ & $49.8(12.7)$ & 0.080 \\
\hline Triglycerides (mean mg/dL \pm SD) & $153.7(68.7)$ & $172.3(72.9)$ & $172.6(62.8)$ & 0.216 \\
\hline PAS (mean mmHg \pm SD) & $133.9(4.3)$ & $132.5(6.0)$ & $132.7(4.8)$ & 0.267 \\
\hline PAD (mean mmHg $\pm \mathrm{SD})$ & $74.4(4.6)$ & $75.3(5.4)$ & $74.3(5.9)$ & 0.499 \\
\hline Steps (mean SD) & $3212.7(604.7)$ & $3369.4(662.3)$ & $3227.1(671.7)$ & 0.336 \\
\hline
\end{tabular}

Results are shown as mean and ( \pm standard deviation) or absolute and (relative) frequencies. IMOAP (motivational intervention of obesity): Structured Motivational Intervention; IMOAP + PA: physical activity platform is added to the IMOAP group; kg: kilograms; BMI: body mass index; $\mathrm{cm}$ : centimeters; $\mathrm{kg} / \mathrm{m}^{2}: \mathrm{kg}$ divided by height in meters squared; HbA1c: glycated hemoglobin; HDL: high density lipoproteins; PAS: systolic blood pressure; PAD: diastolic blood pressure. Comparison between means was made using analysis of the variance of a pathway and a posteriori comparison between groups using the Bonferroni test. Comparison between proportions was assessed using the chi-squared test. *: significant difference between control group and $\mathrm{IMOAP}+\mathrm{PA}$ group

Table 2. Decrease in weight, BMI, and waist circumference between final and initial assessments

\begin{tabular}{|lcccccc|} 
Group (n) & $\begin{array}{c}\text { Weight difference } \\
(\mathbf{k g}) *\end{array}$ & $\boldsymbol{p}$ & $\begin{array}{c}\text { BMI difference } \\
\left(\mathbf{k g} / \mathbf{m}^{2}\right)^{*}\end{array}$ & $\boldsymbol{p}$ & $\begin{array}{c}\text { PC difference } \\
\left(\mathbf{k g} / \mathbf{m}^{2}\right) *\end{array}$ & $p$ \\
\hline G1 (47) & $-1.3(2.3)$ & $<0.001$ & $-0.5(0.8)$ & $<0.001$ & $-1.5(2.5)$ & $<0.001$ \\
\hline G2 (61) & $-4.9(2.2)$ & $<0.001$ & $-1.7(0.7)$ & $<0.001$ & $-4.7(4.4)$ & $<0.001$ \\
\hline G3 (60) & $-6.3(2.3)$ & $<0.001$ & $-2.3(0.9)$ & $<0.001$ & $-8.2(6.6)$ & $<0.001$ \\
\hline Total (168) & $-4.4(3.0)$ & $<0.001$ & $-1.6(1.1)$ & $<0.001$ & $-5.0(5.6)$ & $<0.001$ \\
\hline
\end{tabular}

Results are shown as mean final versus initial $( \pm \mathrm{SD})$. G1: Control group; G2: IMOAP group (Structured Motivational Intervention); G3: IMOAP group to which physical activity platform was added. PC: waist circumference. The comparison between the means was made with the Student's t-test for paired groups.

be treated, especially compared with the control group to achieve the goal of lose weight at least $5 \%$ after 1 year. The reverse RR is shown in the right column to better understand the concept: applying IMOAP with respect to the performance in the control group multiplies by 4.75 the risk of reaching the goal of reducing the weight after a year by $5 \%$. It is multiplied by 7 when instead of IMOAP, IMOAP-AP is applied with respect to the same group. The difference between IMOAP and IMOAP-AP is also significant; performing IMOAP-AP with respect to IMOAP increases the risk of increasing the objective of losing weight by at least $5 \%$ after 1 year. 
Table 3. Modification of the PAS, the PAD, and the number of steps between the final and initial assessments

\begin{tabular}{|lcccccr|}
\hline Group (n) & $\begin{array}{c}\text { PAS difference } \\
(\mathbf{m m H g})\end{array}$ & $\boldsymbol{p}$ & $\begin{array}{c}\text { PAD difference } \\
(\mathbf{m m H g})\end{array}$ & $\boldsymbol{p}$ & $\begin{array}{c}\text { Difference in } \\
\text { number of steps }\end{array}$ & $p$ \\
\hline G1 (47) & $-4.3(7.5)$ & $<0.001$ & $-3.2(6.3)$ & 0.001 & $-91.0(304.5)$ & 0.046 \\
\hline G2 (61) & $-3.0(4.4)$ & $<0.001$ & $-4.0(6.0)$ & $<0.001$ & $205.4(233.6)$ & $<0.001$ \\
\hline G3 (60) & $-5.7(5.8)$ & $<0.001$ & $-5.8(5.0)$ & $<0.001$ & $6735.2(3337.4)$ & $<0.001$ \\
\hline Total (168) & $-4.3(6.0)$ & $<0.001$ & $-4.4(5.8)$ & $<0.001$ & $2454.5(3772.9)$ & $<0.001$ \\
\hline
\end{tabular}

Results are shown as mean final versus initial $( \pm \mathrm{SD})$. G1: Control group; G2: IMOAP Group (Structured Motivational Intervention); G3: IMOAP Group to which physical activity platform is added. PAS: systolic blood pressure; PAD: diastolic blood pressure. The comparison between the means was made with the Student's t-test for paired groups.

Table 4. Modification of total cholesterol, HDL-cholesterol, and triglycerides between the final and initial assessments

\begin{tabular}{|lrrrrrr|} 
& $\begin{array}{c}\text { Difference in } \\
\text { CT }(\mathbf{m g} / \mathbf{d L})\end{array}$ & $\boldsymbol{p}$ & $\begin{array}{r}\text { Difference in } \\
\text { TG }(\mathbf{m g} / \mathbf{d L})\end{array}$ & $\boldsymbol{p}$ & $\begin{array}{c}\text { Difference in } \\
\text { cHDL }(\mathbf{m g} / \mathbf{d L})\end{array}$ & $p$ \\
\hline G1 $(\boldsymbol{n}=\mathbf{4 7})$ & $-5.7(17.3)$ & 0.028 & $1.7(27.0)$ & 0.664 & $1.3(1.1)$ & $<0.001$ \\
\hline G2 $(\boldsymbol{n}=\mathbf{6 1})$ & $-4.7(16.0)$ & 0.027 & $-20.5(46.6)$ & 0.001 & $0.6(2.0)$ & 0.017 \\
\hline G3 $(\boldsymbol{n}=\mathbf{6 0})$ & $-10.1(24.5)$ & 0.002 & $-19.2(32.3)$ & $<0.001$ & $1.7(1.4)$ & $<0.001$ \\
\hline Total $(\boldsymbol{n}=\mathbf{1 6 8})$ & $-6.9(19.8)$ & $<0.001$ & $-13.8(38.0)$ & $<0.001$ & $1.2(1.7)$ & $<0.001$ \\
\hline
\end{tabular}

Results are shown as mean final versus initial $( \pm \mathrm{SD})$. CT: total cholesterol; TG: triglycerides; cHDL: cholesterol bound to high density lipoproteins. G1: Control Group; G2: IMOAP Group (Structured Motivational Intervention); G3: IMOAP Group to which physical activity platform is added. The comparison between the means was made with the Student's t-test for paired data.

Table 5. Modification of glycemia and glycated hemoglobin between final and initial assessments

\begin{tabular}{|lcccr|} 
& $\begin{array}{c}\text { Difference in blood } \\
\text { glucose }(\mathbf{m g} / \mathbf{d L})\end{array}$ & $\boldsymbol{p}$ & $\begin{array}{c}\text { Difference in glycated } \\
\text { hemoglobin }(\%)\end{array}$ & $p$ \\
\hline G1 $(\boldsymbol{n}=\mathbf{4 7})$ & $-1.5(5.0)$ & 0.049 & $0.07(0.1)$ & 0.001 \\
\hline G2 $(\boldsymbol{n}=\mathbf{6 1})$ & $-5.3(5.5)$ & $<0.001$ & $-0.1(0.2)$ & $<0.001$ \\
\hline G3 $(\boldsymbol{n}=\mathbf{6 0})$ & $-5.7(5.2)$ & $<0.001$ & $-0.2(0.2)$ & $<0.001$ \\
\hline Total $(\boldsymbol{n}=\mathbf{1 6 8})$ & $-4.4(5.5)$ & $<0.001$ & $-0.09(0.2)$ & $<0.001$ \\
\hline
\end{tabular}

Results are shown as mean final versus initial $( \pm \mathrm{SD})$. G1: Control Group; G2: IMOAP Group (Structured Motivational Intervention); G3: IMOAP Group to which physical activity platform is added. $\mathrm{mg} / \mathrm{dL}$; milligrams per deciliter. The comparison between the means was made with the Student's t-test for paired data.

\section{DISCUSSION}

The results of the study show that usual interventions to reduce weight are effective after 1 year of application, even in the control group, where there are less than average results, decreased 1,258 $\mathrm{kg}$ (and at least not increased, as an effect rebound observed frequently). But this decrease was more effective in $\mathrm{G} 3(>6 \mathrm{~kg})$ and G2 $(4.9 \mathrm{~kg})$. While the results seem poor, they are relevant since $81.7 \%$ of the $\mathrm{G} 3$ and $65 \%$ achieved a weight loss of at least $5 \%$ compared to only $16.4 \%$ in the control group that achieved it. G3 was five times more effective than G1 in achieving weight loss of $-5 \%$ in1 year. ${ }^{19-23}$ 


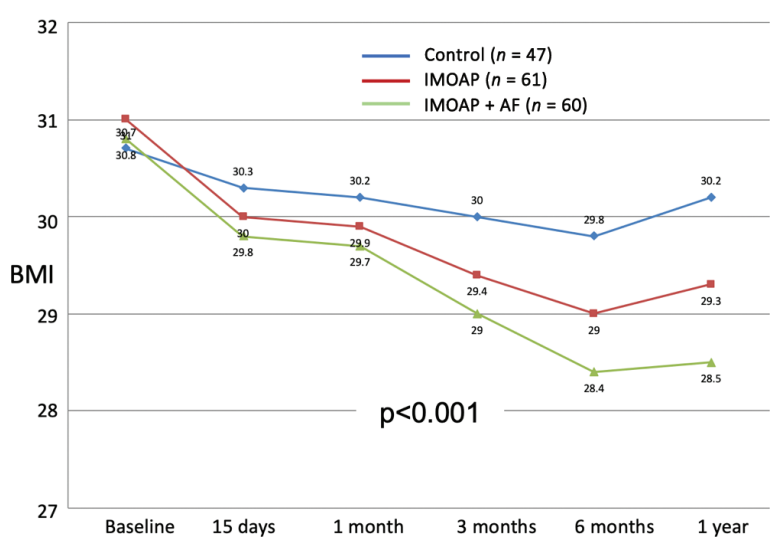

Figure 3-Evolution of the body mass index in each of the groups.

The p-value was calculated by applying the Friedman test to each of the three groups, obtaining the same value for all three $(p<0.001)$. Source: 2018 iwopi participant guide

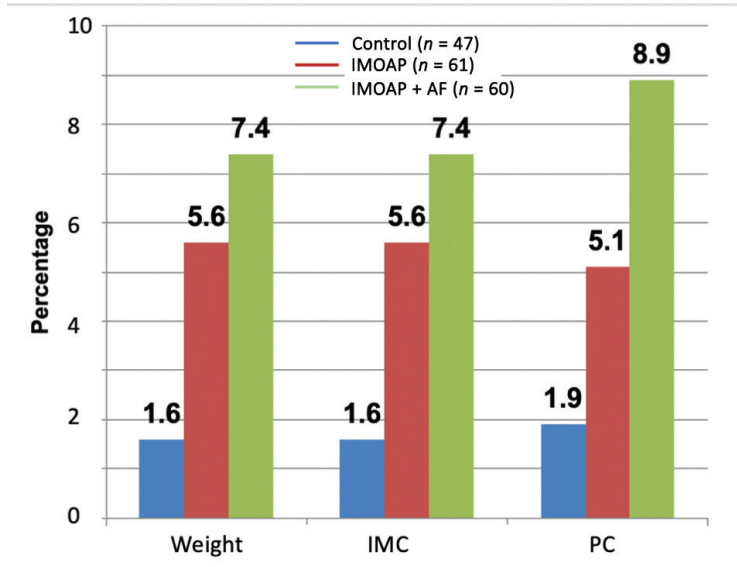

Figure 4-Percentage of weight loss, BMI, and $P C$ (abdominal girth) reached in each of the groups at 12 months of follow-up. IMC: alternative acronym for BMI (body mass index). Source: 2018 iwopi participant guide

During follow-up, one dropout was observed in each intervention group compared with 15 dropouts in the control group, which in our estimation represents an added effect of the motivation program in terms of adherence and compliance.

We demonstrated the effect of motivational group intervention on weight reduction in that $81.7 \%$ of

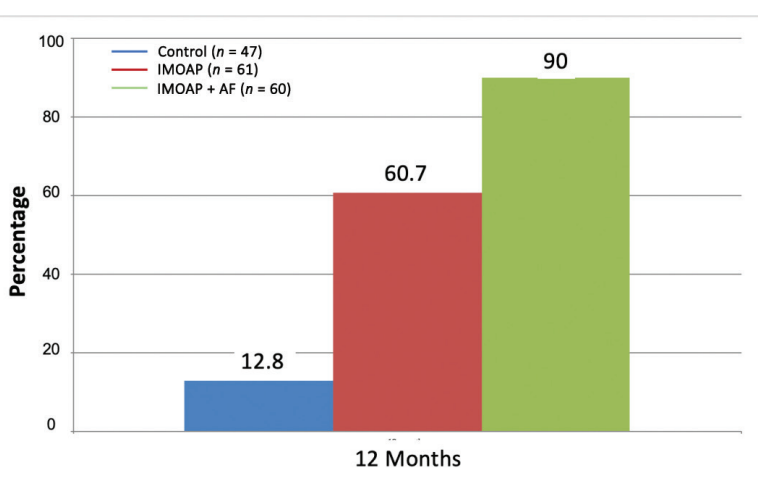

Figure 5-Percentage of patients who achieved the objective of reducing at least $5 \%$ of the weight in each of the groups at 12 months of follow-up. IMOAP: Motivational Intervention Primary Care. EF: Physical exercise. Significant differences were observed among the 3 groups ( $X^{2}$ test: $\left.p<0.001\right)$. Source: 2018 iwopi participant guide

patients in the treatment groups lost at least 5\% by 1 year - a percentage much higher than the control. In G3 group, technologies were used that assessed the monitoring of the level of physical activity (registered on the iwopi platform). ${ }^{19}$

The uses of ICT, such as the Internet, mobile devices, virtual reality, etc., are increasing significantly. ICT offers resources added to traditional programs and improves quality, effectiveness, and efficiency of interventions aimed at chronic problems, such as obesity. In our study, the use of a platform that stimulates physical activity with solidarity destinations has been shown to be effective both to improve program monitoring and to improve health parameters such as weight and lipid parameters.

There are studies in our environment ${ }^{22,23}$ that, with higher investments in structures, have high dropout rates (42\%). Leaving the treatment plan is one of the main problems observed in obesity management studies. In a review of studies of non-pharmacological treatment of obesity, with weight reduction phases of 2-12 months, 
Table 6. Qualitative analysis of patients who achieved the objective of losing $5 \%$ weight after 1 year of follow-up

\begin{tabular}{|c|c|c|c|c|c|c|}
\hline $\begin{array}{l}\text { Comparison } \\
\text { groups }\end{array}$ & $\begin{array}{c}\text { RR } \\
\text { (CI 95\%) }\end{array}$ & $\begin{array}{c}\text { RRR } \\
\text { (CI 95\%) }\end{array}$ & $\begin{array}{c}\text { ARR } \\
(\mathrm{CI} 95 \%)\end{array}$ & $\begin{array}{c}\text { NNT } \\
\text { (CI 95\%) }\end{array}$ & \multicolumn{2}{|c|}{$\begin{array}{c}\text { Inverse RR } \\
\text { (CI 95\%) }\end{array}$} \\
\hline $\begin{array}{l}\text { Control/ } \\
\text { IMOAP }\end{array}$ & $\begin{array}{c}0.21 \\
(0.10 \text { to } 0.46)\end{array}$ & $\begin{array}{c}0.79 \\
(0.54 \text { to } 0.90)\end{array}$ & $\begin{array}{c}0.48 \\
(0.30 \text { to } 0.61)\end{array}$ & $\begin{array}{c}2 \\
\text { (3 to } 2)\end{array}$ & & $\begin{array}{c}4.75 \\
\text { (2.19 to } 10.30)\end{array}$ \\
\hline $\begin{array}{l}\text { Control/ } \\
\text { IMOAP-AF }\end{array}$ & $\begin{array}{c}0.14 \\
(0.07 \text { to } 0.30)\end{array}$ & $\begin{array}{c}0.86 \\
(0.70 \text { to } 0.93)\end{array}$ & $\begin{array}{c}0.77 \\
(0.61 \text { to } 0.86)\end{array}$ & $\begin{array}{c}1 \\
(2 \text { to } 1)\end{array}$ & $\begin{array}{l}\text { IMOAP-PA/ } \\
\text { Control }\end{array}$ & $\begin{array}{c}7.05 \\
\text { (3.32 to } 14.96)\end{array}$ \\
\hline $\begin{array}{l}\text { IMOAP/ } \\
\text { IMOAP-AF }\end{array}$ & $\begin{array}{c}0.67 \\
(0.54 \text { to } 0.84)\end{array}$ & $\begin{array}{c}0.33 \\
(0.16 \text { to } 0.46)\end{array}$ & $\begin{array}{c}0.29 \\
(0.14 \text { to } 0.43)\end{array}$ & $\begin{array}{c}3 \\
\text { (7 to } 2)\end{array}$ & $\begin{array}{l}\text { IMOAP-PA/ } \\
\text { IMOAP }\end{array}$ & $\begin{array}{c}1.48 \\
(1.19 \text { to } 1.85)\end{array}$ \\
\hline
\end{tabular}

RR: relative risk; CI: confidence interval; RRR: relative risk reduction; ARR: absolute risk reduction; NNT: number needed to treat. IMOAP; Physical Activity (AF). The value of $p$ has been calculated by applying the Friedman test to each of the three groups, obtaining the same value for all three $(\mathrm{p}<0.001)$.

Teixeira et al. ${ }^{24}$ observed that the lowest dropout rates were $50-55 \%$ and that often the reason for abandonment was due to a low initial weight reduction..$^{25}$

When analyzing the causes of abandonment in our series, it was observed that in many patients, their socio-cultural environment and intrafamilial difficulties significantly reduced adherence to a program of this nature. In addition, expectations of a greater weight reduction than that observed in the first months of intervention reduced motivation to stay in the program.

In order to improve effectiveness of future programs, it is important to consider the motivation, expectations, and potential difficulties of each person when entering the intervention plan. Factors such as motivation to lose weight, social support, greater capacity to withstand stress, autonomy and greater responsibility for self-care, and greater psychological stability are associated with a greater probability of success in reducing the weight and maintaining the results in the long-term. ${ }^{26}$ In our study, with the motivation program we saw discontinuation at only $4 \%$ in both groups. ${ }^{17,18}$ In the control group, patients were encouraged to be the process managers themselves, with the support of the health center. They were informed that regular weight registration, better adherence to the Mediterranean diet pattern, and increased physical activity were related to better results in terms of weight loss. ${ }^{17}$

It was brought to our attention that weight registration could be done at the health center, and there were digital resources that could improve adherence to changes in eating patterns and physical activity.

While the recommendation to lose weight should be given to all overweight or obese patients, ${ }^{27}$ many studies have shown that this does not happen in clinical practice. In most, the recommendation of weight loss is between 20 and $36 \%,{ }^{18,19,21}$ although in the study by Phelan et al., $75.5 \%$ was reached. ${ }^{28}$ This lack of systematic recommendation happens despite recognition that patients who receive this advice from their family doctors are twice as likely to achieve a weight loss compared to those who did not received it. ${ }^{29,30}$ There is no consensus on the barriers that explain this phenomenon, although perhaps the most invoked are economic management, lack of motivation by the patient, and lack of time and training of the professionals. ${ }^{18,19}$ 
The results from this group show that $16.4 \%$ of the patients presented a weight loss $\geq 5 \%$. This is remarkable because the studies in our environment ${ }^{19-23}$ show, as in other populations, that the tendency of the adult population is to gradually increase body weight. Reversing this trend can be an instrument not sufficiently valued and that can be useful in the management of this authentic pandemic.

The results of our study are in line with those published by Allen et al. ${ }^{31}$ where, with a less intensive intervention and with technological support, participants achieved an average weight loss of $3.3 \mathrm{~kg}$ with a BMI decrease of $1.1 \mathrm{~kg} / \mathrm{m}^{2}$. This study compared four different types of intervention (intensive with nutritional coaching, intensive with nutritional coaching and app support, less intensive intervention with app support, and only app support).

This behavior occurs in many of the follow-up studies, since weight loss is much more difficult after the first months. The differences between these groups reached statistical significance. On the other hand, the results of our study are superior to those of Carter et al. ${ }^{24}$ whose patients followed by a digital platform presented a 6-month weight loss of $-1.3 \mathrm{~kg}$ (95\% confidence interval [CI]: 2.7 to 0.1 ) with a BMI change of $-0.5 \mathrm{~kg} / \mathrm{m}^{2}$ (95\% CI: -0.9 to 0.0$)$.

However, we are far from reaching the recently published results of the retrospective study of the cohort of users of the Noom Coach app, ${ }^{32}$ in which a significant reduction in weight obtained in $22.7 \%$ of participants was higher at $10 \%$, unlike our study in which the anthropometric data are those objectified by the healthcare professional, in that the results are those reported by the users themselves on the app. The study included participating app users who had registered them at least two times a month for 6 months, with an average follow-up of 267 daysalmost 9 months. It should be noted that this is a population with an average BMI of $30.2 \pm$ $0.1 \mathrm{~kg} / \mathrm{m}^{2}$ in men (grade I obesity) and $28.0 \pm$ $0.0 \mathrm{~kg} / \mathrm{m}^{2}$ in women (overweight). While in our study we found no differences in relation to gender, in this cohort weight loss was greater in the male population, related to greater use of the app. This inferiority of our results would be congruent, since adherence to the app is greater than to the digital platform; and that of the platform is superior to that made with paper support. ${ }^{24-26}$

The visits were done at the first month and after every 3 months, including advice on life-style changes, physical exercise, and hypo-caloric diet containing 1.200-1.500 Kcal and anthropometric measurements (weight, height, and waist).

Our study does not allow us to determine the influence the weight registration control factor had on health professionals and which had the use of the digital tool. Although the analysis shows that patients who started with an initial level of adherence of 6.7 points improved with their use, so that at the end of the study adherence was 12.1 points. On the one hand, numerous studies show that simple weight monitoring can facilitate weight loss or maintenance once the loss has occurred. On the other hand, we know that greater adherence to physical activity is followed by weight optimization. In the Carrasco study, ${ }^{27}$ on adherence to physical activity and long-term weight change, the group with greater adherence to physical activity showed a lower risk of weight gain.

\section{CONCLUSIONS}

Our results lead us to propose that we apply new technologies to measure adherence to physical activity and, subsequently, to use them to improve levels of adherence. Further research 
will be necessary to measure different programs for this purpose - programs that include different, intelligent monitoring processes that adhere to the user's profile and may include gamification.

\section{Funding: None}

\section{Conflict of Interest: None}

Contributors Contributions: Fatima Madrona Marcos, Josefa M. Panisello, Loreto Tarraga Marcos, and Pedro J. Tarraga Marcos contributed to the design, methodology, results and analysis, and elaboration. Nuria Rosich contributed to methodology, results, and analysis. Julio A. Carbayo Herencia and Josep Alins recorded the results and analysis.

\section{REFERENCES}

1. Popkin BM, Adair LS, Ng SW. Now and then: The global nutrition transition: The pandemic of obesity in developing countries. Nutr Rev. 2012;70(1):3-21.

2. Flegal KM, Kruszon-Moran D, Carroll MD, Fryar CD, Ogden CL. Trends in obesity among adults in the United States, 2005 to 2014. JAMA. 2016;315(21): 2284-91.

3. Aranceta-Bartrina J, Pérez-Rodrigo C, Alberdi-Aresti G, Ramos-Carrera N, Lázaro-Masedo S. Prevalencia de obesidad general y abdominal en la población adulta española (25-64 años) 2014-2015: Studio ENPE. Rev Esp Cardiol. 2016;69:579-87.

4. Jensen MD, Ryan DH, Donato KA, et al. Guidelines (2013) for managing overweight and obesity in adults. Obesity. 2014;22: S1-410.

5. Seger JC, Horn DB, Westman EC, et al. Obesity Algorithm, presented by the American Society of Bariatric Physicians. [cited 2015 March 10]. Available from: http://www.asbp.org/ obesityalgorithm.html.
6. Clinical guidelines on the identification, evaluation, and treatment of overweight and obesity in adults - The evidence report. National Institutes of Health. Obes Res. 1998;6(Suppl 2):51S-209S.

7. Jakicic JM, Winters C, Lang W, Wing RR. Effects of intermittent exercise and use of home exercise equipment on adherence, weight loss, and fitness in overweight women: A randomized trial. JAMA. 1999;282:1554-60.

8. DiPietro L, Stachenfeld NS. Exercise treatment of obesity. In: De Groot LJ, Chrousos G, Dungan K, et al., editors. Endotext [Internet]. South Dartmouth, MA: MDText.com, Inc.; 2000 [updated 2017 Aug 9]. Available from: https://www.ncbi. nlm.nih.gov/books/NBK278961/

9. Wadden TA, Butryn ML, Byrne KJ. Efficacy of lifestyle modification for long-term weight control. Obes Res. 2004;12(Suppl):151S-62S.

10. Wadden TA, West DS, Neiberg RH, et al. One-year weight losses in the Look AHEAD study: Factors associated with success. Obesity (Silver Spring). 2009; 17:713-22.

11. Perez-Martinez P, Garcia-Rios A, DelgadoLista J, Perez- Jimenez F, Lopez-Miranda $\mathrm{J}$. Mediterranean diet rich in olive oil and obesity, metabolic syndrome and diabetes mellitus. Curr Pharm Des. 2011;17(8): 769-77.

12. Beunza J-J, Toledo E, Hu FB, et al. Adherence to the Mediterranean diet, long-term weight change, and incident overweight or obesity: The Seguimiento Universidad de Navarra (SUN) cohort. Am J Clin Nutr. 2010;92(6):1484-93.

13. Matheson GO, Klügl M, Engebretsen L, et al. Prevention and management of noncommunicable disease: The IOC consensus statement, Lausanne 2013. Br J Sports Med. 2013;47(16):1003-11. https:// doi.org/10.1136/bjsports-2013-093034

14. Eysenbach G. What is e-health? J Med Internet Res. 2001;3(2):e20, https://doi. org/10.2196/jmir.3.2.e20 
15. Riley W, Augustson EM. Mobile phonebased smoking cessation interventions increase long-term quit rates compared with control programmes, but effects of the interventions are heterogeneous. Evid Based Nurs. 2013;16(4):108-9. https://doi. org/10.1136/eb-2012-101204

16. Wieland LS, Falzon L, Sciamanna $\mathrm{CN}$, et al. Interactive computer-based interventions for weight loss or weight maintenance in overweight or obese people. Cochrane Database Syst Rev. 2012;8:CD007675. https://doi. org/10.1002/14651858.CD007675.pub2.

17. Garvey WT, Garber AJ, Mechanick JI, et al. American Association of Clinical Endocrinologists and American College of Endocrinology position statement on the 2014 advanced framework for a new diagnosis of obesity as a chronic disease. Endocr Pract. 2014;20: 977-89.

18. Garvey WT. New tools for weight-loss therapy enable a more robust medical model for obesity treatment: Rationale for a complications-centric approach. Endocr Pract. 2013;19:864-74.

19. Tárraga Marcos ML, Rosich N, Panisello Royo JM, et al. Eficacia de las estrategias de motivación en el tratamiento del sobrepeso y obesidad. Nutr Hosp. 2014;30:741-8.

20. Wadden TA, Webb VL, Moran CH, Bailer BA. Lifestyle modification for obesity: New developments in diet, physical activity, and behavior therapy. Circulation. 2012;125:1157-70. [PubMed: 22392863]

21. Moher D, Hopewell S, Schulz KF, et al. CONSORT 2010 explanation and elaboration: Updated guidelines for reporting parallel group randomised trials. J Clin Epidemiol. 2010;63:1-37.

22. Serra L, Ribas L, Aranceta J, Pérez C, Saavedra P, Pena L. Obesidad infantil y juvenil en España. Resultados del Estudio enKid (1998-2000). Med Clin (Barc). 2003;121:725-732.
23. Gutiérrez-Fisac JL, Banegas JR, Rodríguez $\mathrm{F}$, Regidor E. Increasing prevalence of overweight and obesity among Spanish adults, 1987-1997. Int J Obes. 2000;24:1677-82.

24. Teixeira PJ, Going SB, Sardinha LB, Lohman TG. A review of psychosocial pretreatment predictors of weight control. Obes Rev. 2005;6:43-65.

25. Ponce-Garcia I, Simarro-Rueda M, CarbayoHerencia J et al. See more Prognostic value of obesity on both overall mortality and cardiovascular disease in the general population. PLoS ONE. 2015;10(5).

26. Allen JK, Stephens J, Dennison Himmelfarb CR, Stewart KJ, Hauck S. Randomized controlled pilot study testing use of smartphone technology for obesity treatment. J Obes. 2013;Article ID 151597:212-19. https://doi. org/10.1155/2013/151597

27. Carrasco F, Moreno M, Irribarra V, et al. Evaluation of a pilot intervention program for overweight and obese adults at risk of type 2 diabetes. Rev Méd Chile. 2008;136:13-21.

28. Phelan S, Nallari M, Darroch FE, Wing RR. What do physicians recommend to their overweight and obese patients? J Am Board Fam Med. 2009;22:115-22.

29. Galuska DA, Will JC, Serdula MK. Are health care professionals advising obese patients to lose weight? JAMA. 1999;282:1576-8.

30. Sciamanna CN, Tate DF, Lang W, Wing RR. Who reports receiving advice to lose weight? Results from a multi-state survey. Arch Int Med. 2000;160:2334-9.

31. Allen J, Stephens J, Dennison Himmelfarb Ch, Stewart KJ, Hauck S. Randomized controlled pilot study testing use of smartphone technology for obesity treatment. J Obes. 2013;2013:151597.

32. Chin SO, Keum C, Woo J, et al. Successful weight reduction and maintenance by using a smartphone application in those with overweight and obesity. Sci Rep. 2016; $7: 1-8$. 
Copyright Ownership: This is an open access article distributed in accordance with the Creative Commons Attribution Non Commercial (CC BY-NC 4.0) license, which permits others to distribute, adapt, enhance this work non-commercially, and license their derivative works on different terms, provided the original work is properly cited and the use is non-commercial. See: http:// creativecommons.org/licenses/by-nc/4.0. 